\title{
Fragaria vesca Chlorophyll Mutants
}

Thomas M. Davis and James E. Pollard

Dept. of Plant Biology, University of New Hampshire, Durham, NH 03824

Additional index words. strawberry, genetics, induced mutation

Despite the successful history of strawberry breeding (Bringhurst and Voth, 1984), relatively little is known of strawberry genetics (e.g., Arulsekar et al., 1981; Mok and Evans, 1971). Genetic studies of the commercially cultivated strawberry, Fragaria $\times$ ananassa Duchesne $(2 \mathrm{~N}=8 \mathrm{X}=56)$, are hampered by genetic complexity at the octoploid level (Arulsekar et al., 1981). Because the AAA'A'BBBB genomic constitution of $F . \times$ ananassa incorporates the AA genomes of diploids $F$. vesca and $F$. viridis (Senanayake and Bringhurst, 1967), genetic analysis of diploid strawberries may provide insight into the genetic constitution and behavior of the cultivated strawberry (Arulsekar and Bringhurst, 1983; Brown and Waring, 1965).

Only a few morphological (Brown and Waring, 1965; Richardson, 1914, 1918) and isozyme (Arulsekar et al., 1981) variants of diploid strawberries have been genetically characterized. We mutagenized $F$. vesca 'Baron Solemacher' with the objective of identifying new and useful genetic markers in a diploid strawberry.

Seeds of 'Baron Solemacher' (Johnny's Selected Seeds, Albion, Maine) were imbibed under moist cotton overnight, then exposed to a ${ }^{137} \mathbf{C s}$ source for $60 \mathrm{~min}$, receiving

Received for publication 24 Aug. 1989. Scientific contribution no. 1640 from the New Hampshire Agricultural Experiment Station. The cost of publishing this paper was defrayed in part by the payment of page charges. Under postal regulations, this paper therefore must be hereby marked $a d$ vertisement solely to indicate this fact. an estimated y-irradiation dose of $7.5 \mathrm{krad}$. $\mathrm{M}_{2}$ and $\mathrm{M}_{3}$ generation seed production resulted from natural self-pollination of $\mathrm{M}_{1}$ and $\mathrm{M}_{2}$ plants, respectively, under greenhouse conditions.

Among $90 \mathrm{M}_{2}$ families grown for evaluation, four contained stable chlorophyll mutants. In families 456, 502, and 648, mutant seedlings (mutants M456, M502, and M648, respectively) had light green, yellow, and white shoots, respectively, and died at the cotyledon or first true leaf stage. Light green seedlings of mutant M538 were viable, grew to sexual maturity, and produced only light green progeny when allowed to self-pollinate in the greenhouse.

Normally pigmented siblings in $\mathbf{M}_{2}$ families 456, 502, 538, and 648 were all fully viable; a proportion $(8 / 13,6 / 15,4 / 15$, and $7 / 15$, respectively) of these normal $M_{2}$ plants produced $\mathrm{M}_{3}$ families that segregated for the respective chlorophyll abnormalities, showing that each mutant phenotype was inherited in a recessive manner.

When $\mathrm{M}_{3}$ phenotypic segregation patterns (within segregating $M_{3}$ families) were tested for goodness-of-fit to a 3:1 ratio, only mutant M502 [521 normal: 191 yellow $\left(\mathrm{X}^{2}=\right.$ 1.17 n.s.)] fit the monogenic expectation. Observed deviations from 3:1 for M456 [547 normal : 122 light green $\left(\mathrm{X}^{2}=15.8^{* *}\right)$, M538 [109 normal :55 light green $\left(\mathrm{X}^{2}=\right.$ 5.93*)], and M648 [376 normal :52 white $\left.\left(\mathrm{X}^{2}=37.0^{* *}\right)\right]$ may have been due to gametic or zygotic selection against (M456, M648), or in favor of (M538) the mutant type, or perhaps to multiple factor inheritance.
Mutants M456, M502, M538, and M648, which can all be phenotypically classified at seedling emergence, will be useful in linkage and other genetic studies in strawberry. Additionally, the M538 mutation has potential value as a marker for estimation of outcrossing rates. F. vesca is regarded as a predominantly self-pollinating species (Arulsekar and Bringhurst, 1981). However, when seeds were harvested from M538 plants grown in a field among a population of normal 'Baron Solemacher' plants, 240 out of 522 of the resulting seedlings were dark green. Whether this apparent outcrossing rate of $46 \%$ was due to specific reproductive characteristics of mutant M538 or was truly representative of normal 'Baron Solemacher' remains to be determined. Mutants M456, M502, M538, and M648 are available to interested researchers upon request to the authors.

\section{Literature Cited}

Arulsekar, S. and R.S. Bringhurst. 1983. Strawberry, p. 391-400. In: S.D. Tanksley and T.J. Orton (eds.) Isozymes in plant genetics and breeding, part B. Elsevier, Amsterdam.

Arulsekar, S., R.S. Bringhurst, and V. Voth. 1981. Inheritance of PGI and LAP isozymes in octoploid cultivated strawberries. J. Amer. Soc. Hort. Sci. 16:679-683.

Bringhurst, R.S. and V. Voth. 1984. Breeding octoploid strawberries. Iowa State J. of Res. 58:371-381.

Brown, T. and P.F. Waring. 1965. The genetical control of the everbearing habit and three other characters of Frugaria vesca. Euphytica 14:97112.

Mok, D.W.S. and W.D. Evans. 1971. Chromosome association at diakinesis in the cultivated strawberry. Can. J. Genet. Cytol. 13:231-236.

Richardson, C.W. 1914. A preliminary note on the genetics of Fragaria. J. Genet. 3:171-177.

Richardson, C.W. 1918. A further note on the genetics of Fragaria. J. Genet. 7:167-170.

Senanayake, Y.D.A. and R.S. Bringhurst. 1967. Origin of Fragaria polyploids. I. Cytological analysis. Amer. J. Bet. 54:2.21-228. 